\title{
O IMPACTO DAS NOVAS TECNOLOGIAS EDUCACIONAIS NO NOVO CONTEXTO DE EDUCAÇÃO HÍBRIDA NO BRASIL
}

\author{
THE IMPACT OF NEW EDUCATIONAL TECHNOLOGIES ON THE NEW \\ CONTEXT OF HYBRID EDUCATION IN BRAZIL
}

\begin{abstract}
Fabiano Della Silva ${ }^{1}$
RESUMO: Este artigo apresenta a importância das novas Tecnologias da Informação e Comunicação (TIC) para o processo de ensino-aprendizado prioritariamente no contexto de isolamento social provocado pelo advento da chegada do COVID-I9 no Brasil e também no mundo. Desta forma, este trabalho busca verificar a disseminação dessas novas tecnologia e a importância destas não só neste momento de isolamento social más também a sua importância em um contexto mais abrangente e as perspectivas futuras para a educação brasileira. Desta forma, o trabalho irá relacionar as novas tecnologias dentro do processo de ensino-aprendizagem buscando a sua relação com os estudantes e os professores e também os pontos de atenção que devem ser tomados em relação à estas tecnologias e como estas poderão ser utilizadas como uma espécie de alavanca para a promoção do aprendizado significativo e na melhoria dos métodos para o ensino. Para tanto, foi construído um estudo bibliográfico sobre as novas tecnologias de acordo com a visão de alguns teóricos sobre o assunto no intuito de levantar trabalhos que possam contribuir para o processo de alavancagem do conhecimento.
\end{abstract}

Palavras-chave: Tecnologias; Informação; Comunicação; Métodos.

ABSTRACT: This article presents the importance of new Information \& Communications Technology (ICT) for the teaching-learning process, primarily in the context of social isolation caused by the advent of the arrival of COVID-Ig in Brazil and also in the world. In this way, this work seeks to verify the dissemination of these new technologies and the importance of these not only in this moment of social isolation but also their importance in a broader context and the future perspectives for Brazilian education. In this way, the work will relate new technologies within the teaching-learning process seeking their relationship with students and teachers and also the points of attention that must be taken in relation to these technologies and how they can be used as a use kind of lever for promoting meaningful learning and improving teaching methods. To this end, a bibliographic study on the new technologies was built according to the view of some theorists on the subject in order to raise studies that can contribute to the process of leveraging knowledge.

Keywords: Technologies; Information; Communication; Methods.

\footnotetext{
${ }^{1}$ Engenheiro de Produção Civil e Licenciado em Matemática. MBA em Gerenciamento de Projetos e Mestre em Engenharia. E-mail: fabianodella@gmail.com.
} 


\section{INTRODUÇÃO}

Desde o início da pandemia de COVID-19 provocado pelo Corona Vírus que se iniciou em março de 2020 que a sociedade mundial e principalmente aqui no Brasil iniciou-se uma discussão de forma mais aguda a respeito de formas não convencionais de trabalho remoto, de atendimento a clientes e também de ministração aulas de forma remota. Desta forma, o home-office, o teletrabalho e também o Homeschooling, que eram antigamente somente uma forma alternativa às convencionais existentes, hoje, mais do que nunca, se tornaram, em alguns momentos na pandemia, as únicas formas de se fazer alguma coisa e, nos demais períodos da pandemia, foram utilizadas de formas híbrida junto às outras formas existentes antes da pandemia.

O interessante que, algumas vezes, temos a percepção de que as mudanças de paradigmas quase que sempre ela ocorre de forma imposta e, no caso da pandemia, muitas empresas, profissionais liberais e escolas tinham em seu portfólio as formas remotas somente como algo "imaginário" ou algo "muito distante" de ocorrer e daí, com a chegada da pandemia, estas formas que antes eram apenas algo improvável, se tornou algo inevitável e algo muito presente na atualidade. Com base nisso, a inovação quase sempre nasce como resposta a um problema, demanda ou desafio da sociedade e, é possível supor que, ao nos depararmos com um cenário de adversidade, estamos lidando com uma oportunidade ímpar para propormos transformações significativas e que podem mudar a forma como enxergamos o mundo à nossa volta. Podemos ver relatos de pessoas dizendo que a empresa a qual elas trabalham não houve perdas com o trabalho remoto. Muito pelo contrário. O que vemos hoje são relatos de que empresas que gastavam milhões com aluguéis ou com imóveis locados, hoje, mudaram as suas operações com todo ou a maior parte do seu time no trabalho no formato remoto.

É por saber das grandes vantagens e possibilidades que podem ser implementadas com a utilização das novas tecnologias no processo de ensino-aprendizagem que desde a década de 80 que se discute aqui no Brasil a importância da utilização da tecnologia no ambiente escolar como principal objetivo dinamizar a relação estudante $\mathrm{x}$ professor $\mathrm{x}$ aprendizagem através do uso de ferramentas da informática como o computador e a internet além de softwares específicos para cada disciplina ensinada. A partir de 1982 o Ministério da Educação e Cultura (MEC) propôs um desafio para que os próprios brasileiros criassem os seus programas de computador que até então eram oriundos de outros países e não eram adequados à diversidade cultural brasileira. Conforme vimos em Pellandra (2000), o processo de ensino-aprendizagem deve ser referido como um processo que desenvolve sujeitos de forma que os estudantes ao invés de ser um mero receptor de informações oriundas de um professor, ele passa a ser um agente ativo no processo chamado "aprender a 
aprender".

Este artigo tem como objetivo principal de investigar através de uma criteriosa revisão bibliográfica como a tecnologia tem influenciando a forma de ensinar nas escolas nos dias atuais, sobretudo nos dias de pandemia e isolamento social. Desta forma, este trabalho busca verificar também buscar a relação destas tecnologias com os estudantes e os professores e também os pontos de atenção que devem ser tomados em relação à estas tecnologias e como estas poderão ser utilizadas como uma espécie de alavanca para a promoção do aprendizado significativo e na melhoria dos métodos para o ensino. Como objetivos específicos, o trabalha busca verificar como está o engajamento dos professores em relação às novas tecnologias e buscar as perspectivas de avanço destas tecnologias. O artigo está estruturado da seguinte forma: na seção I temos a introdução ao tema. $\mathrm{Na}$ seção 2 temos a fundamentação teórica enquanto na seção 3 temos a metodologia para a realização do trabalho e, por fim temos a seção 4 com as considerações finais.

\section{FUNDAMENTAÇÃO TEÓRICA}

Nas escolas, hoje temos muitos estudantes com aulas no formato híbrido, que é uma combinação entre aulas presenciais e aulas no formato remoto. Outra grande quantidade de estudantes hoje tem aulas somente no formato remoto. É perceptível também que muitos profissionais da educação hoje confessam que não imaginavam os resultados que estão presenciando hoje com as aulas nos formatos remoto ou híbrido, coisa que não era imaginável antes da pandemia. É notável que a sociedade ainda não está totalmente preparada para as aulas totalmente remotas visto que ainda existem problemas estruturais e de infraestrutura que já existiam antes, como a falta de internet ou internet de boa qualidade, faltam professores qualificados, faltam infraestrutura física, computadores, materiais escolares, dentre outros.

Já percebeu que quando nos referimos à tecnologia quase sempre pensamos na palavra informática onde a qual significa "informação automática", ou seja, a utilização de métodos e técnicas no tratamento automático da informação. O termo tecnologia vem do grego que significa "arte", "ofício" ou "técnica” em junção com a palavra estudo denotando ser um encontro entre a ciência e a engenharia. Em poucas palavras, podemos dizer que:

(...) o berço da tecnologia vem da Filosofia Moderna, seus principais representantes depositaram, como nunca antes, total confiança na razão humana enquanto esclarecedora do mundo das coisas. Além do próprio Galileu que parece ter nascido em um momento inoportuno para suas ideias, Francis Bacon, Pascal, Berkeley, Newton, Leibniz, Thomas Hobbes, Espinosa, Locke e Descartes foram os principais pensadores que deram início ao que viria se cristalizar depois na Filosofia do Iluminismo em meados do século XVIII, tendo como fonte quase que onipotente e onipresente, a razão humana (SCRIBD, 20II). 
Existem variados conceitos de tecnologia da informação, porém, se destaca o de Cruz (1997): "É o conjunto de dispositivos individuais, como hardware, e software, telecomunicações ou qualquer outra tecnologia que faça parte ou gere tratamento da informação, ou ainda, que a contenha". O conceito de Telemática proposto por Mattelart e Schmucler (1983) se trata de um conjunto de equipamentos eletrônicos que armazenam, processam e disseminam informações:

\begin{abstract}
"Os novos sistemas de comunicação e informação, situados na intercessão da informática, das telecomunicações e dos meios audiovisuais, são sistemas complexos e interconectados. (...) A convergência de numerosas redes por onde circulam os fluxos de informação até um ponto único, a tela do terminal de computador - que bem pode ser a do televisor domiciliar - indica a impossibilidade de isolar, em nossos dias, os campos até pouco tempo dissociados da informação notícia, da informação - entretenimento e da informação - controle social."
\end{abstract}

Este conceito vem ao encontro do que pode ser visto em Bulhões (200I) onde o autor destaca que as novas tecnologias da informação e comunicação (as TICs) representam um desafio ainda maior que aquele inicialmente dimensionado pelos seus analistas, ou seja, este conceito torna ainda mais claro o reconhecimento das vantagens proporcionadas pelas novas tecnologias, no que diz respeito à racionalização burocrática, à economia de tempo e de pessoal nas organizações complexas, à agilização dos fluxos informativos para atender às demandas dos cidadãos e facilitar a solução dos problemas cotidianos

Em função de tudo o que foi dito até então, podemos entrar em comum acordo de que as TICs puderam ajudar de forma muito oportuna e gratificante frente às novas necessidades criadas não só em função do advento da chegada da pandemia, como também da própria mudança de conceito que está havendo em nossa necessidade. As novas TICs aplicadas na educação se mostram atualmente ferramentas úteis para tornar mais dinâmico o processo de ensino-aprendizagem e caso estas sejam aplicadas com criatividade e responsabilidade, estas podem apresentar benefícios inigualáveis para os estudantes e também para todos os agentes envolvidos no processo de ensinoaprendizagem. Os aparatos tecnológicos têm se mostrados cada vez mais populares nestes dias atuais e as novas gerações certamente poderão ter estes equipamentos trabalhando em prol da construção do seu aprendizado e os agentes educacionais e também os familiares dos estudantes não devem ficar alheios a essas tecnologias.

É sabido que o papel do professor em sala de aula tem mudado com o passar do tempo sendo que hoje em dia, ele se mostra mais como um mediador do processo de ensino-aprendizagem e não mais como antigamente como um ser intocável e que era o "possuidor do saber". Neste intuito, podemos ver em Tébar (20II) que a experiência tem nos ensinado que o ritmo das nossas aprendizagens vem crescendo qualitativa e quantitativamente à medida que este conhecimento vem 
marcado por bons professores através da sua mediação. Desta forma, o processo de mediação vem nos trazer como objetivo a construção de habilidades e conhecimentos de forma que o sujeito possa adquirir a autonomia no saber. $\mathrm{O}$ mesmo autor ainda reforça que a mediação tem como ponto de partida um princípio antropológico positivo que é a crença da potencialização e da perfectibilidade do ser humano e, desta forma, devemos compreender o processo da mediação como uma posição humanizadora, positiva, construtiva e potencializadora no complexo mundo da relação educativa.

Este processo de mediação do conhecimento em sala de aula se torna ainda mais interessante para os atores do processo de ensino-aprendizagem quando colocamos neste processo elementos que podem promover a aprendizagem significativa através de jogos, animações, materiais manipuláveis, etc. e sabemos que as novas tecnologias poderão atuar como parte fundamental neste processo fazendo um elo ainda maior entre o professor e o estudante seja em sala de aula ou seja através do ensino remoto. Segundo Silva (2020), existem muitos benefícios oriundos das novas tecnologias na educação onde podem ser enumeradas cinco principais como I) tornar as aulas mais atrativas; 2) Despertar a curiosidade e atenção dos estudantes; 3) Melhorar a produtividade; 4) Auxiliar os educadores a dinamizar as aulas e 5) Contribuir para o aproveitamento escolar extraclasse.

\section{I.I TECNOLOGIAS AUDIOVISUAIS NA EDUCAÇÃO}

Audiovisual é uma palavra ou um termo genérico para se referir a formas de comunicação que combinam som e imagem ou também a cada produto gerado por estas formas de comunicação, ou à tecnologia empregada para o registro, tratamento e exibição de som e imagem sincronizados, ou ainda à linguagem utilizada para gerar significados. A TV, o rádio, o computador juntamente com a internet se configuram como meios de comunicação audiovisual e são considerados recursos importantes para auxiliar o processo de ensino-aprendizado e estão mais próximos do cotidiano dos estudantes. Existem autores que defendem que estas tecnologias devem ser utilizadas na escola e trazidas para o processo educacional, porém, devem serem utilizados de forma criativa, crítica e respeitando a realidade dos estudantes, tornando o ambiente de aprendizado muito mais dinâmico, rico de ideias e dentro do contexto social dos estudantes.

Todos nós sabemos da grande influência da televisão em nossa sociedade atual e, historicamente já era notado um interesse em se criar um aparelho de TV desde o século XIX e, através da aplicação de conceitos da matemática, da física e também na química, por volta do ano de 1842, Alexander Bain conseguiu colocar em prática e executar um projeto de envio telegráfico de imagem. Segundo Moran (2007), a televisão tem formado de forma predominante e ao longo de muito tempo a forma de ver o mundo dos brasileiros, alimentando o seu universo sensorial, afetivo 
e ético de todas as faixas etárias dos brasileiros e estas culturas são levadas para a sala de aula e, portanto, o educador tem dificuldade em contrapor através de uma visão mais crítica ou sugerir um universo mais abstrato, complexo e, contudo, na contramão da maioria como a escola se propõe a fazer. $O$ autor ainda argumenta que existem uma diferença entre as narrativas dos meios de comunicações e da escola e que a linguagem imposta na escola bate de frente com a TV por se mostrar uma linguagem mais distante e intelectualizada e se mostrando mais cansativa para os estudantes se comparada com a linguagem que os estudantes estão acostumados a ver na TV.

Desde há muito tempo já é percebida uma resistência no meio pedagógico em relação a adoção de tecnologias audiovisuais no processo de ensino-aprendizagem na escola em função de inúmeros projetos existentes que não foram concluídos, assim como o processo de formação profissional dos professores e também na utilização destas tecnologias por eles mesmos em suas vidas cotidianas. Ao longo do tempo, foi criada uma concepção de que o uso de imagens audiovisuais e também a sua transmissão pelos meios de comunicação em sala, não estavam condizentes com os objetivos da escola. Mesmo sabendo que a televisão faz parte da formação histórico cultural das crianças, foi percebido que, mesmo assim, esta tecnologia ainda não estava sendo utilizada com uma aliada na educação. Estes fatos fizeram com que fosse criada ao longo do tempo uma certa resistência, fazendo com que a linguagem em sala de aula ficasse reduzida somente à interpretação técnica ou em alguns momentos o reforço da técnica pela técnica (LINHARES, 2005).

Del Rio (1997) apud Litwin (1997), acrescenta:

“A escola especializou-se em dizer coisas que a criança considera certas mas não reais (à margem do plano do sentido, não significativas para a vida) enquanto que a televisão lhe dá coisas reais, embora nem sempre certas. Aceitar este paradoxo é natural para as novas gerações. A escola aceitou esta pouco construtiva divisão. (...) Deixa assim toda a tecnologia dos novos meios e sistemas simbólicos e a do sentido (a realidade, o saber vinculado à ação) para a cultura extra escolar.”

Esta resistência tem trazido grande dificuldade de se incorporar a linguagem audiovisual no dia a dia escolar e essa mentalidade cria uma cegueira e um pavor contra o novo, e as novas tecnologias, que para Levy (1995) atinge seu ápice "quando antigas técnicas são declaradas culturais e impregnadas de valores, enquanto as novas são denunciadas como bárbaras e contrárias à vida".

É grande a quantidade de atividades que podem ser desenvolvidas em sala de aula através da utilização de tecnologias audiovisuais, em especial TV e vídeo, de forma a enxergar gêneros orais específicos como: entrevista, debate, reportagem, conversa semi-informal, reportagem, comentário, instruções, propaganda, publicidade, teleteatro, telenovela, teleteatro interativo, documentários, narração de acontecimentos (jogos, eventos, acidentes, catástrofes, fatos políticos), narrativas de ficção etc. 
De acordo com Moran (2007), existe um abismo entre a comunicação entre o professor e os estudantes em função da comunicação do professor ser mais sequencial, abstrata e erudita sendo que os estudantes pensam mais sensorial, concreta, plástica e multimídica em função das crianças e jovens navegar mais na internet, ver mais TV e participarem mais ativamente de jogos eletrônicos se comparado com os professores. $\mathrm{O}$ autor ainda reforça que, neste caso, o professor deverá focar mais na relação afetiva de forma a motivá-los, incentivá-los e surpreendê-los. Fazendo isso, os professores terão mais facilidade em introduzir novos assuntos e fazer a turma se sentir mais participativa.

A escola deverá acompanhar as tendências das novas tecnologias e de que forma estas estão sendo inseridas no contexto dos estudantes de forma que os agentes educacionais possam estudar a forma mais adequada de incorporar estas novas tecnologias no processo de ensino-aprendizagem para que este legado possa facilitar o aprendizado significativo junto aos estudantes.

\subsection{A TECNOLOGIA E O PROCESSO DE ENSINO-APRENDIZAGEM}

Temos uma grande facilidade em atribuirmos o termo tecnologia quando estamos nos referindo a aparelhos smartfones, tablets ou uma nova invenção de um processador mais rápido, contudo, devemos saber que o temo tecnologia é muito mais amplo e se trata de qualquer artefato, método ou técnica que foi criada pelo homem de forma a alterar ou melhorar as suas condições de trabalho, a sua forma de locomoção ou de comunicação tornando estas muito mais favoráveis para o seu dia a dia. Formas simples de criação e utilização simples de tecnologia é a utilização de ferramentas, como por exemplo, a descoberta pré-histórica de como controlar o fogo e, logo em seguida, a revolução neolítica, onde pudemos notar uma forte mudança de estilo de vida do homem, passando de caçador-coletor e nômade para um estilo de cultura agrícola e mais fixa. Estes fatos de forma combinada aumentaram consideravelmente a disponibilidade de fontes de alimento, enquanto a invenção da roda também veio auxiliar aos seres humanos a viajar, transportar as suas colheitas e insumo além de controlar também o seu ambiente. De acordo com Chaves (2007), se considerarmos este sentido mais amplo da tecnologia ela não se trata de algo e, na verdade, ela se configura algo tão velho quanto o próprio homem.

Em se tratando da relevância das tecnologias para a educação, Chaves (2007) explana:

Nem todas as tecnologias inventadas pelo homem são relevantes para a educação. Algumas apenas estendem sua força física, seus músculos. Outras apenas lhe permitem mover-se pelo espaço mais rapidamente e/ou com menor esforço. Nenhuma dessas tecnologias é altamente relevante para a educação. No entanto, as tecnologias que amplificam os poderes sensoriais do homem, sem dúvida, o são. O mesmo é verdade das tecnologias que estendem a sua capacidade de se comunicar com outras pessoas. Mas, acima de tudo, isto é verdade das tecnologias, disponíveis 
hoje, que aumentam os seus poderes mentais: sua capacidade de adquirir, organizar, armazenar, analisar, relacionar, integrar, aplicar e transmitir informação.

Se trata de um grande equívoco acharmos que as Tecnologias na Educação se restringem somente aos computadores, dispositivos eletrônicos e outros equipamentos que podem ser ligados à internet. É interessante lembrar que o fato de que a fala humana, a escrita, as aulas, o quadro negro, o giz, os livros e as revistas, etc. também são tecnologias que foram inventadas e que vêm sendo utilizadas pelos educadores há muito tempo e que certamente seria quase inconcebível vivermos hoje sem estas tecnologias.

Outro equívoco relacionado às novas tecnologias é achar que estas servirão somente para suportar as velhas metodologias tradicionais de ensino ou que as tecnologias servirão somente como um recurso didático inovador. É importante que as inovações tecnológicas sejam percebidas não só no contexto do processo de ensino-aprendizagem em sala de aula como também na vida cotidiana dos professores e alunos fazendo com que seja necessário de forma contínua a construção de um novo processo de ensino-aprendizagem nos diversos setores da educação de forma que os avanços tecnológicos venham acrescentar a este novo processo valores e competências nas atividades voltadas ao ensino-aprendizagem.

A aplicação das tecnologias não está destinada somente para nos trazer agilidade nas soluções de problemas, para trazer mais conforto e praticidade à realização de atividades cotidianas, más sim, elas estão presentes de forma disseminada na sociedade, ou seja, estão presente nas fábricas, nas indústrias, nas empresas, nos hospitais e diversos outros setores e a educação não poderia ficar de fora deste contexto tecnológico. A falta de conhecimento em relação ao potencial dos novos recursos tecnológicos e a forma de como serão incorporados no processo ensino aprendizagem levam os professores a resistirem a utilizarem os mesmos na prática educativa, como estratégia de aprendizagem.

Por outro lado, não podemos pensar na utilização das novas tecnologias somente como algo "legal" ou porque "as outras pessoas estão usando" ou "não devemos ficar de fora" ou algo deste tipo. Temos que refletir sobre o modelo pedagógico a qual esta tecnologia está inserida, temos que pensar nas estratégias de aprendizagem para alcançar os resultados previamente definidos e escolher a tecnologia como meio de se alcançar estes resultados. A dica é que façamos convergir o modelo, a estratégia, a tecnologia e o propósito de ensinar característico de cada docente. Não podemos pensar na tecnologia como uma figura central no processo educativo, mas sim, os professores e os estudantes. De acordo com Lévy (1999), “o professor torna-se um animador da inteligência coletiva dos grupos que estão ao seu encargo. Sua atividade será centrada no acompanhamento e na gestão 
das aprendizagens: incitamento à troca de saberes, a mediação relacional e simbólica, a pilotagem personalizada dos percursos de aprendizagem, etc.”. Demo (1995) reforça esta ideia quando diz que "a educação precisa ser um processo emancipatório e deixar de ser domesticador."

De acordo com Lévy (1993), "novas maneiras de pensar e conviver estão sendo elaboradas no mundo das telecomunicações e da informática. As relações entre os homens, o trabalho, a própria inteligência depende na verdade, da metamorfose dos dispositivos informacionais de todos os tipos. [...]”. É notável que nem todos os agentes educacionais estão tão motivados ou receptivos em relação às novas tecnologias de modo que, sobre este aspecto, Quartierro e Bianchetti (1999, p. 247-248), através das suas observações, explicitam que os professores podem ser classificados em quatro grupos distintos: I) os apologetas, 2) os apocalípticos, 3) os indiferentes e, 4) os que procuram posicionar-se e aprender as novas tecnologias como elas são. Para o grupo dos apologetas, laudatários ou deslumbrados com a capacidade dos indivíduos objetivarem sua inteligência nas máquinas, só existem pontos positivos nas novas tecnologias, além de estarem sempre a par da última inovação tecnológica, a consideram responsável pela melhoria de vida da população. Já o grupo dos apocalípticos, ao contrário do primeiro grupo, só veem coisas ruins nas tecnologias. Para este segundo grupo, a televisão é responsável pela desagregação familiar, o telefone impede a aproximação física das pessoas, a máquina de calcular limita o raciocínio, o computador está substituindo e colocando o homem a seu serviço, etc. Para grupo dos indiferentes, acomodados ou ensimesmados que fazem parte do terceiro grupo, essas tecnologias não fazem parte de seu dia a dia, pois já estão velhos demais para assimilar essa nova cultura. Ficam assim alheios às transformações que estão ocorrendo à sua volta. O quarto grupo é formado por educadores que procuram posicionar-se e apreender as novas tecnologias como elas são: criação humana, carregadas de ideologias, capazes de contribuir para facilitar a vida, mas quando indevidamente usadas, favorecem a submissão das pessoas ao poder instituído de quem constrói, domina e possui. Este quarto grupo estão os professores que enxergam que as novas tecnologias são uma grande aliada frente a um desafio de uma educação que forme indivíduos capazes de serem protagonistas das suas próprias escolhas e conseguem pensar por si mesmos e são capazes de encarar as mudanças na sociedade.

\subsection{INTELIGÊNCIA ARTIFICIAL NA EDUCAÇÃO}

Podemos definir a Inteligência Artificial (IA) como uma área das ciências da computação que tem por objetivo a produção de dispositivos que podem simular a capacidade do ser humano de raciocinar, perceber, resolver problemas e tomar decisões que, a partir de um estímulo do ambiente externo, realiza uma ação baseada na análise de dados de interações anteriores fazendo com que este 
sistema aprende com ele mesmo. Uma solução envolvendo a IA se trata de um agrupamento de várias tecnologias combinadas, como redes neurais artificiais, algoritmos, sistemas de aprendizado, entre outros que conseguem simular capacidades humanas ligadas à inteligência, como por exemplo, o raciocínio, a percepção do ambiente externo e a habilidade de análise de dados para a tomada de decisões. A IA também é um campo da ciência que tem por propósito estudar, desenvolver e empregar máquinas para realizarem atividades humanas de maneira autônoma podendo estar também ligada à robótica, ao Machine Learning (Aprendizagem de Máquina), ao reconhecimento de voz e de visão, entre outras tecnologias.

A aplicação do computador na educação durante os últimos 20 anos tem se mostrado ser de grande valia para o processo de ensino-aprendizagem (BECK, 1998), (URBAN-LURAIN, 1998). Segundo McArthur (1993) e Beck (1998), os primeiros sistemas desenvolvidos para o ensino através da utilização do computador foram o CBT - Computer-Based Training (treinamento baseado em computador) e a CAI - Computer Assisted Instructional (instrução baseada em computador). Segundo os autores, e também reforçado por Urban-Lurain (1998), estes sistemas geravam conjuntos de problemas projetados para aumentar o desempenho do estudante em domínios baseados em habilidades, como aritmética e recuperação de vocabulário. Nestes sistemas, a instrução não era individualizada para as necessidades do estudante. A proposta era apresentar um problema ao estudante, registrar a resposta e avaliar seu desempenho e, de acordo com Beck (1998), as decisões a respeito de como o estudante deveria navegar dentro do material era baseada em árvores de decisão.

O método de ensino baseado em investigação são métodos que tem sido discutido nos últimos anos e que procuram explorar aspectos não existentes nos sistemas de ensino tradicionais. Estes sistemas são entendidos como sistemas de ensino interativos e, de acordo com Aguiar (2007), seus principais princípios são:

- Construção e não instrução: o objetivo é explorar o fato de que estudantes podem aprender mais efetivamente através da construção de seu próprio conhecimento.

- O controle é do estudante e não do tutor: a questão é dar mais liberdade para o estudante controlar suas interações no processo de aprendizado. $O$ tutor deve atuar como um guia, e não como o único detentor do conhecimento.

- A individualização é determinada pelo estudante e não pelo tutor: diferentemente dos sistemas tradicionais, a personalização da informação é o resultado da interação com o ambiente. Esta responsabilidade pode estar também associada ao sistema, mas o estudante ainda terá uma boa parte do controle de sua individualização.

- O conhecimento adquirido pelo estudante é resultado de suas interações com o sistema e não com o tutor: a informação adquirida vem como uma função das escolhas e ações do estudante no ambiente de ensino e não como um discurso gerado pelo tutor. 
Como foi percebido, estes princípios sugerem uma mudança de enfoque que, nos sistemas tradicionais este enfoque é dado ao tutor e, nesta nova visão, o enfoque passa ser centrado no estudante.

\subsection{RECURSOS DIGITAIS EM SALA DE AULA}

As tecnologias digitais poderão gerar novas demandas para o viver acadêmico além de modificar e empoderar procedimentos já existentes e consagrados em diversas disciplinas. De acordo com a Revista Nova Escola (2009), existem inúmeras sugestões de práticas pedagógicas utilizando as tecnologias digitais, como por exemplo, computadores ou outros dispositivos com aplicativos de edição de textos como o Word onde o professor pode sugerir a construção de redações seguidas de correções de ortografia com os próprios estudantes. Em termos de organização textual, existe a vantagem em poder mudar os textos de lugar, fazer ampliações, cortes e eliminar frases e parágrafos, experimentando novas soluções para a composição sem precisar escrever tudo de novo a cada nova versão.

É importante reforçar que nenhuma das inovações tecnológicas substitui o trabalho clássico na disciplina, centrado na resolução de problemas. As estratégias como cálculo mental, contas com algoritmos e criação de gráficos e de figuras geométricas com lápis, borracha, papel, régua, esquadro e compasso seguem sendo essenciais para o desenvolvimento do raciocínio matemático. Contudo, saber usar calculadoras e conhecer os princípios básicos de planilhas eletrônicas do tipo Excel são hoje demandas sociais pois os estudantes certamente irão utilizar estas ferramentas no seu dia a dia profissional. O professor como mediador do conhecimento deve introduzir esses recursos nas aulas de forma muito cuidadosa pois deve pontuar que eles não fazem mágica e são apenas instrumentos para auxiliar e nos trazer produtividade.

Já o vídeo, por exemplo, na forma de DVD ou através da internet, é muito útil nas aulas de educação física. Segundo a Revista Nova Escola (2009), com o vídeo, é possível que o professor trabalhe as práticas corporais por meio da apreciação. A exemplo dos esportes menos populares ou esportes que são impraticáveis na escola, como o Hipismo ou o Judô, mas podem ser estudados em sala de aula por causa das tecnologias. No caso do Judô, preparar uma atividade em vídeo, por exemplo, pode servir para explicar as regras que não ficam claras nas transmissões dos Jogos Olímpicos na TV.

Em se tratando da disciplina História, a Revista Nova Escola (2009) sugere a internet como uma fonte muito vasta para pesquisas. Com claros objetivos em mãos e orientados pelos professores em sala é muito provável que se possa tirar muito proveito de tanta riqueza. Em seguida, é importante discutir onde encontrar informação confiável e a origem dos conteúdos pesquisados. 
Nesse ponto, o trabalho do professor é ensinar que os fatos históricos ensinados pelos livros ou outras fontes de informações sempre são carregados com um certo nível de opinião própria do autor e que os fatos nem sempre são contados de maneira neutra.

Em disciplinas onde é necessária a utilização de figuras, as tecnologias de imagens com mapas virtuais que podem ser mostrados com a utilização de internet no lugar de mapas físicos em sites como o Google Maps e programas como o Google Earth possibilitam a visualização de partes do globo em versão cartográfica, imagens de satélite, fotos aéreas e até em ${ }_{3} \mathrm{D}$ - algumas vezes, com uma resolução que permite perceber características das construções, quantidade de árvores e até de carros em uma paisagem. É importante lembrar que os mapas e atlas impressos continuam tendo utilidade, porém, aprender a utilizar a cartografia digital nos permite converter o aluno em sujeito ativo do processo de construção da informação geográfica.

É através das tecnologias que é possível ampliar a experimentação e a observação de procedimentos muito importantes ao método científico. Como exemplo, para a disciplina de Português, temos tecnologias como as ferramentas de publicação de textos, os processadores de texto como o Word além de sites de áudio e vídeo. Na disciplina de Geografia, temos a internet com programas de cartografia, GPS e mapas online que podem ser acessados de forma gratuita em sala de aula. Na disciplina de história, existe a internet com vários conteúdos sobre vários acontecimentos históricos que podem ser utilizados como base para a explicação de algum assunto dentro da disciplina. Enfim, existem aplicativos e simuladores que podem ser utilizados de forma gratuita ou também pagos e que são muito úteis no processo de ensino-aprendizagem.

\subsection{PONTOS DE ATENÇÃO A RESPEITO DAS TECNOLOGIAS}

Em se tratando das tecnologias visuais, alguns aspectos interessantes podem ser problemáticos quando estamos buscando materiais de qualidade para os estudantes. Por exemplo, os vídeos não são classificados quanto a sua qualidade de imagem e som e também aos aspectos mais subjetivos, porém, não menos importantes como as propriedades técnicas e outras relacionadas aos sentidos e às emoções. Outro problema é a indicação dos vídeos em relação às suas finalidades, como por exemplo, um vídeo pode ser tecnicamente ultrapassado, mas funcionar como um documento histórico, ou para análise do momento histórico e social da época em que foi criado, ou ainda por tratar de forma competente de um conteúdo curricular. Um vídeo pode trazer algum erro conceitual pode ser usado para que os alunos identifiquem e discutam possíveis erros. Um vídeo que aborde algum assunto a partir de uma visão politicamente incorreta pode ser discutido pelos alunos como contraponto na construção de visão crítica de mundo. 
Mandarino (200I), critica em seu trabalho em relação ao critério dominante para a escolha de um vídeo por um professor, que é a indicação do mesmo por outro professor e isto está diretamente atrelada à alegação de tempo comentado por parte dos professores. Segundo o autor, seria muito gratificante se pudéssemos encontrar critérios mais objetivos como uma análise, comentários, as atividades planejadas e as suas avaliações do que foi feito efetivamente. Napolitano (1999) acrescenta e reconhece as dificuldades encontradas na prática docente como o excesso da carga de trabalho, a falta de tampo, a má remuneração, etc.

Existem também problemas relacionados com a escolha do software e muitas vezes os professores não têm uma noção mínima de como realizar a análise deste software. Este problema seria solucionado se existisse um planejamento estruturado entre os professores de suas áreas especificas e os professores dos laboratórios de informática. Por exemplo, a escolha de um jogo virtual sem o critério pedagógico adequado e muitas vezes são colocados somente como uma forma de "preencher" espaços de tempo ociosos. Segundo Mandarino (2002), existem muitos softwares educativos, porém são poucos os que trazem algum benefício por serem incompletos. De acordo com Fischer (1997), o educador deve estar atento ao seguinte:

a) o professor deve observar qual o papel do aluno no decorrer de sua aprendizagem a partir do software;

b) o software deve ampliar as possibilidades de interação professor-aluno;

c) o software deve prever o tratamento de erro do aluno no programa, ou seja, deve permitir avaliar o tipo de dificuldade mostrada pelo aluno e apresentar, ao mesmo tempo, atividades alternativas para a superação do erro;

d) o programa ou jogo deve apresentar níveis crescentes de assimilação e acomodação de novos conhecimentos. Cada etapa vencida deverá ser uma subestrutura para a etapa seguinte.

Dentro da visão de ensino tradicional, existe um mecanismo onde o professor impõe os seus conhecimentos de maneira autoritária. O conceito de ensino interacionalista, de acordo com Piaget (1998), a criança precisa amadurecer apenas fisiologicamente e, a partir disto, haverá a prontidão necessária para ele aprender. Nesse sentido, para Piaget, basta apenas um excelente laboratório e pronto, ela aprenderá sozinha pela interação com o meio. No conceito sociointeracionista trazido por Vygotsky, a concepção de ensino-aprendizagem prioriza a análise dos reflexos do mundo exterior no interior dos indivíduos, por meio da interação deles com a realidade a qual estes indivíduos estão inseridos. Neste conceito trata da dimensão sociocultural do estudante, valorizando o contexto histórico, social e cultural em que está inserido. Essa proposta valoriza as atividades em grupo, a linguagem e o relacionamento interpessoal, partindo do pressuposto de que o desenvolvimento 
histórico acontece do social para o individual. Contudo, de acordo com Piaget (1998), apesar de todas as vantagens já conhecidas trazidas pelas tecnologias, não é apenas o uso destas que será possível mudar o contexto educacional do país, contudo a busca por novas formas de ensinar irá renovar a dinâmica da educação. Dentro deste mesmo contexto, Brunner (20oı) reforça que não se deve cometer o erro de imaginar que a mudança educacional será guiada apenas pela existência das novas tecnologias da informação e comunicação, por mais disruptivas que estas possam ser. A educação é muito mais que seus suportes tecnológicos: encarna um princípio formativo, é uma tarefa social e cultural que, sejam quais forem às transformações que experimente, continuará dependendo, antes de tudo, de seus componentes humanos, de seus ideais e valores.

\subsection{A TECNOLOGIA COMO ALAVANCA NO ENSINO REMOTO NO BRASIL}

De acordo com Lima (2020), existe uma janela de oportunidade para que o cenário pós pandemia, através da utilização de tecnologias educacionais, possa ser promissor. $O$ autor afirma que o cenário após a pandemia tem um lado muito bom que pode ser aproveitado que é a alavancagem do sistema de ensino híbrido. Por outro lado, Lima (2020) fica receoso em relação às diferenças ou as desigualdades educacionais que poderão aumentar pois ele afirma que as instituições de ensino estavam bem avançadas no que diz respeito ao ensino remoto para os adultos e necessita ainda de alguns avanços para que este cenário seja replicado para o ensino de crianças e adolescentes, como por exemplo, a criação de comunidades entre outros estudantes para que a construção do conhecimento seja compartilhada e haja interação entre os estudantes

As startups e empresas de tecnologia, dentro deste contexto de quarentena e restrições, assumem um papel decisivo em propor soluções para o mercado através de aplicações de tecnologias já existentes e também na criação de outras novas como aliadas importantes para a educação de jovens e adultos no Brasil. $\mathrm{O}$ ambiente educacional atual já consegue utilizar já há algum tempo ferramentas já conhecidas como as plataformas de EAD e as soluções de gestão educacional, porém, outras tecnologias podem ganhar destaque contribuir muito para uma mudança nas dinâmicas de ensino existentes no Brasil. Como exemplo delas, as ferramentas de mobile learning, que podem atender populações em diferentes locais do país que utilizam o celular como principal forma de acesso à internet; de tecnologias assistivas e portais de cursos adaptados para comunidades de portadores de deficiência; de plataformas que contribuem para a difusão da leitura e aprendizagem dos chamados soft skills; e até de ferramentas mais sofisticadas que utilizam dados e gamification para a criação de jornadas personalizadas de ensino e aprendizagem.

Como podemos constatar, neste período de quarentena, o mercado de tecnologia educacional 
brasileiro já conta com soluções já bastante difundidas dentro de alguns campos de atuação e que estão contribuindo com a manutenção, com a promoção e também com a aquisição de novos conhecimentos. Portanto, é necessário que os atores envolvidos no processo de ensino-aprendizado estejam todos comprometidos com os problemas educacionais de forma que estes atores venham se utilizar das novas ferramentas educacionais não só como pano de fundo para a manutenção das práticas pedagógicas já existentes, como também como ferramenta alavanca como resposta para os desafios como a evasão escolar, baixo engajamento de estudantes e modelos de ensino pouco adaptados à realidade dos estudantes brasileiros.

É notório que as novas tecnologias puderam amortecer um pouco os impactos negativos da pandemia nos dias atuais pois, caso estivéssemos um uma pandemia desta magnitude há duas ou três décadas atrás, certamente teríamos nenhum tipo de aula e as escolas muito provavelmente estariam fechadas por um período de tempo muito longo o que prejudicaria muito o calendário acadêmico. Por outro lado, segundo Coifman (2021), o advento da utilização com maior frequência das tecnologias "evidenciou problemas, como a desigualdade social e de acesso às tecnologias. Ou seja, nem todos conseguem desfrutar dos benefícios oferecidos, e isso acaba privilegiando alguns grupos em detrimento de outros". O autor reforça que, para que tenhamos ganhos mais sustentáveis, o mais importante é que as instituições realmente invistam no processo de transformação digital e isso não significa apenas a adoção de novas ferramentas. Uma verdadeira revolução na educação depende também de uma mudança de mindset e da capacitação de todos os envolvidos, sobretudo do corpo docente e administrativo. Dominar todos os recursos é essencial para conseguir engajar os estudantes, oferecer a melhor qualidade de ensino possível e conquistar bons resultados.

\section{METODOLOGIA}

Como o próprio nome já sugere, a metodologia de uma pesquisa tem por finalidade a abordagem dos caminhos trilhados, ou seja, os métodos utilizados para que os objetivos de uma pesquisa sejam atingidos. A metodologia não é importante somente em um trabalho acadêmico, como o TCC, um artigo, etc. mas também em situações reais no dia a dia de funcionários de empresa em quaisquer análises seja ela técnica, econômica, a escolha da metodologia se faz imprescindível, pois como já foi visto acima, ela ditará qual o caminho ou abordagem do problema a ser resolvido. Desta forma, uma metodologia é a justificativa para a abordagem de uma pesquisa e é a lente através da qual a análise ocorre. Uma metodologia também se trata de uma ferramenta que descreve a estratégia geral de uma pesquisa que dita a maneira pela qual a pesquisa deve ser realizada. A metodologia deve impactar quais métodos para um empreendimento de pesquisa são selecionados, a 
fim de gerar dados convincentes.

Com relação aos procedimentos, para este artigo, optou-se pela pesquisa bibliográfica e entende-se por pesquisa bibliográfica a revisão de documentos científicos como artigos, dissertações, teses, livros, periódicos, etc. Com relação à abordagem da pesquisa foi optado pela abordagem qualitativa pois, nesta abordagem, existe um levantamento e coleta de dados e informações sobre as motivações de um grupo que são mais subjetivos na busca de compreender e de interpretar determinados comportamentos, opinião, expectativa, sentimentos, percepções, entre outros aspectos imateriais.

Em se tratando dos objetivos desta pesquisa, optou-se pela pesquisa explicativa de modo que esta venha identificar os fatores determinantes dos fenômenos relacionados aos problemas aqui levantados. De acordo com pode ser observado em Minayo (1993), "a pesquisa qualitativa responde a questões muito particulares. Ela se preocupa, nas ciências sociais, com um nível de realidade que não pode ser quantificado, ou seja, ela trabalha com o universo de significados, motivos, aspirações, crenças, valores e atitudes, o que corresponde a um espaço mais profundo das relações dos processos e dos fenômenos que não podem ser reduzidos à operacionalização de variáveis. (p. 2I)".

No mesmo ímpeto, Fiorentini e Lorenzato (2006, p.IIo), destacaram que a abordagem qualitativa "busca investigar e interpretar o caso como um todo orgânico, uma unidade em ação com dinâmica própria, mas que guarda forte relação com seu entorno e contexto sociocultural”. É uma metodologia onde o pesquisador "procura explicitar as causas dos problemas ou fenômenos, isto é, busca o porquê das coisas. É comum a pesquisa explicativa apoiar-se numa investigação exploratória ou descritiva". Esses autores ainda reforçam que as pesquisas descritivas e explicativas podem envolver o "Levantamento bibliográfico, realização de entrevistas, aplicação de questionários ou testes, ou até mesmo estudo de casos".

\section{${ }_{4}$ CONSIDERAÇÕES FINAIS}

Através deste trabalho foi possível perceber que a sociedade ainda não está preparada para as aulas totalmente remotas pelo fato de ainda existirem problemas estruturais que já existiam muito antes da pandemia, como a falta de internet ou internet insuficiente, falta de professores qualificados, falta de infraestrutura física como computadores, materiais escolares, etc. Foi constatado também por muitos autores que o advento da utilização mais frequente das novas tecnologias deixou claro problemas como a desigualdade social e de acesso às tecnologias pela população mais pobre.

As novas TICs utilizadas na educação se mostram como importantes ferramentas tornando o processo de ensino-aprendizagem mais dinâmico e, no que diz respeito à racionalização burocrática, 
à economia de tempo e de pessoal nas organizações complexas, à agilização dos fluxos informativos nas instituições de ensino e também em outras organizações da sociedade.

Portanto, muitos autores afirmam que estas novas tecnologias poderão apresentar benefícios inigualáveis para os estudantes e todos os demais envolvidos no processo de ensino-aprendizagem se forem aplicadas com criatividade, responsabilidade, criatividade, criticidade e respeitar a realidade dos estudantes, tornando o ambiente de aprendizado mais dinâmico, rico de ideias e dentro do contexto social deles. Estas ferramentas são muito promissoras como resposta para os desafios como a evasão escolar, baixo engajamento de estudantes e modelos de ensino pouco adaptados à realidade dos estudantes brasileiros.

Pudemos verificar através deste trabalho que se trata de um equívoco achar que as tecnologias servirão somente para suportar as velhas metodologias tradicionais de ensino ou que servirão somente como um recurso didático inovador, porém, as inovações tecnológicas deverão ser inseridas não só no contexto em sala de aula como também na vida cotidiana dos professores. É importante que as inovações ocorram nos diversos setores da educação de forma que os avanços tecnológicos venham acrescentar a este novo processo valores e competências nas atividades voltadas ao ensino-aprendizagem.

Foi possível notar também que nem todos os agentes educacionais estão motivados ou receptivos com relação às novas tecnologias. Existe um grupo de professores que ainda não enxergam a tecnologia como um aliado para o ensino e isto está relacionado com o processo de formação destes profissionais que ainda necessita ser ajustado. Existem também problemas ligados à escolha do software onde os professores quase sempre não têm uma noção mínima de como realizar a análise do mesmo. Este problema possivelmente será solucionado com a existência de um planejamento estruturado entre os professores de suas áreas especificas e os professores dos laboratórios de informática.

Portanto, é necessário que todos os envolvidos no processo de ensino-aprendizado estejam comprometidos com os problemas educacionais de forma que venham se utilizar das novas ferramentas educacionais não só como pano de fundo para a manutenção das práticas pedagógicas já existentes, más também como forma de criar uma verdadeira revolução na educação através da mudança de mindset e da capacitação de todos os envolvidos, sobretudo do corpo docente e administrativo. 


\section{REFERÊNCIAS}

AGUIAR, Juliana; HERMOSILLA, Lígia. Aplicações da Inteligência Artificial na Educação. REVISTA CIENTÍFICA ELETÔNICA DE PSICOLOGIA. Ano IV - Número o6 - fevereiro de 2007 - Periódicos Semestral.

BECK, J.; STERN, M.; HAUGSJAA, E. Applications of AI in education: the ACM's first electronic publication, 1998. Disponível em: 〈http:// www.acm.org/crossroads/xrds3-I/aied.html〉 Acessado em i8 fevereiro de 2007.

BRUNNER, José J. Educação no encontro com as novas tecnologias. 202I. In TEDESCO, Juan Carlos (org), Educação e novas tecnologias, esperanças ou incertezas? São Paulo: Cortez, 2004.

BULHÕES, Paulo N. S. As novas tecnologias de informação e comunicação (TICs) no ensino de administração: opiniões de professores e alunos do curso de administração da UFRN. Natal: UFRN, 2001 .

CHAVES, Eduardo O. C. Tecnologia na Educação. 2007. Disponível em 〈http://smeduquedecaxias.rj.gov.br/nead/Biblioteca/Forma\% $\mathrm{C}_{3} \% \mathrm{~A}_{7} \% \mathrm{C}_{3} \% \mathrm{~A}_{30} \% 20$ Continuada/ Tecnologia/chaves-tecnologia.pdf> Acesso em 03/03/2021.

COIFMAN, A. Entenda como a tecnologia educacional contribuirá para a adaptação do ensino. Blog Lyceum. 2021. Disponível em < https://blog.lyceum.com.br/tecnologia-educacional/> Acessado em 13 de março de 2021

CRUZ, Tadeu. Sistemas, organização \& métodos. São Paulo: Atlas, 1997.

DEMO, P. Educação e qualidade. 2.ed. Campinas: Papirus, 1995.

FISCHER, E. \& REUBER, A.R. (1997). The Influence of the Management Team's International Experience on the Internationalization Behaviors of SMEs. Journal of International Business Studies, Vol. 28, No. 4, pp. 807-825.

LÉVY, P. Cibercultura. Rio de Janeiro: Ed. 34, 1999.

LIMA, A. R. Tecnologia na Educação em Tempos de Quarentena. Revista Científica E-Locução, I(I7), 5. 2020. Disponível em http://periodicos.faex.edu.br/index.php/e-Locucao/article/view/256 Acessado em 25 de fevereiro de 2021

LINHARES, Ronaldo Nunes. Educação/Comunicação: O Uso Do Audiovisual Em Sala de Aula (2005). Disponível em: <encipecom.metodista.br/mediawiki/images/2/2c/GTio_-_oog.pdf> Acessado em 23 de janeiro de 2011.

LITWIN, Edith. (org.) Tecnologia educacional: política, histórias e propostas. Porto Alegre: Artes Médicas, 1997 .

LORENZATO, Sérgio (org.). O Laboratório de Ensino de Matemática na formação de professores. Ia. Ed. Campinas, SP: Autores Associados, p. 3-37, 2006 (Coleção Formação de Professores). 
MANDARINO, Mônica C. F. O Perfil das Escolas Pólo: Um Estudo a partir dos Dados da Pesquisa: Indicadores Metodológicos para Produção e Utilização do Vídeo Educativo. Rio de Janeiro, 2ooI

MANDARINO, Mônica C. F. Organizando o trabalho com vídeo em sala de aula. Universidade do Rio de Janeiro - UNIRIO. Morpheus - Revista Eletrônica em Ciências Humanas - Ano or, número oI, 2002.

MINAYO, M. C. S. Pesquisa social: Teoria, método e criatividade. Rio de Janeiro: Vozes, 1993.

MCARTHUR, D.; LEWIS, M.W.; BISHAY, M. The Roles of Artificial Intelligence in Education: Current Progress and Future Prospects, 1993. Disponível em: http://www.rand.org/hot/mcarthur/Papers/role.html, Acessado em 05 de março de 202I.

MORAN, José Manuel. Desafios da televisão e do vídeo à escola. In: Desafios na Comunicação Pessoal. 3ํㅡㄹ Ed. São Paulo: Paulinas, 2007.

MATTELART, Armand; SCHMUCLER, Héctor. América Latina em La encrucijada telemática. México: Fólios, 1983.

PELlANDA, Nilze Maria Campos; PELlANDA, Eduardo Campos (org.). Ciberespaço: um hipertexto com Pierre Lévy. Porto Alegre: Artes e Ofício, 2000.

PIAGET, Jean. A formação do símbolo na criança: imitação, jogo e sonho, imagens e representação. Rio de Janeiro: Guanabara, 1998.

QUARTIERO, E. M.; BIANCHETTI, L. O entremesclamento do trabalho pedagógico com as novas tecnologias da informação e comunicação. In:RAYS, O. A. (Org.). Trabalho pedagógico. Porto Alegre: Sulina, 1999. p. 238-254.

REVISTA NOVA ESCOLA ON LINE. Prática pedagógica - o uso dos recursos digitais nas diversas disciplinas. Edição n. 223, 2009. Disponível em: http://revistaescola.abril.com.br/educacaofisica/pratica-pedagogica/atividadesvideoaulas-educacao-fisica-476orı.shtml Acessado em 23 de janeiro de 20II.

SCRIBD. O que é a tecnologia e onde ela surgiu. Disponível em: http://www.scribd.com/doc/2057221/O-que-e-tecnologia-e-onde-ela-surgiu Acessado em 26 de janeiro de 20II.

SILVA, Gabriele. Os benefícios das novas tecnologias na educação. Site Educa Mais Brasil. março de 2020. Disponível em: https://www.educamaisbrasil.com.br/educacao/noticias/os-beneficiosdas-novas-tecnologias-na-educacao. Acessado em 04 de março de 202I.

TÉBAR, Lorenzo. O perfil do professor mediador: pedagogia da mediação. Tradução Priscila Pereira Mota. São Paulo: Senac São Paulo, 2011.

URBAN-LURAIN, M. Intelligent tutoring systems: an historic review in the context of the development of artificial intelligence and educational psychology, 1998. Disponível em: http://www.cse.msu.edu/ urban/ITS.htm Acessado em Io de março de 2007. 